\title{
Research on Operation and Control of Micro-Grid System
}

\author{
Cunxu Wang, Xingfeng Xiao, Aijun Zhang and Xiaoyu Sun \\ Shenyang Institute of Engineering, Shenyang, China \\ wangcx@sie.edu.cn
}

\begin{abstract}
Micro-grid is the significant part of the distribution network in the future of smart grid, which has advanced and flexible operation and control pattern, and integrates distributed clean energy. It is a study of the direction of the grid in the future. In the paper, it gives an account of the operation and control of micro-grid. First, the concept of micro-grid, the structure and characteristics of the typical micro-grid and the significance of the development of micro-grid are analyzed. Second, it introduces typical control strategy which contains the integrated control strategy of Micro-grid and a typical control mode of Micro-power. At last, based on a comprehensive control strategy, it proposed the operation mode of Micro-grid.
\end{abstract}

Keywords: Micro-grid, Control Strategy, Operating mode

\section{Introduction}

With the social development and technological advancement, the demanding of electricity continues to increase. Expanding the scale of the grid, the traditional centralized power generation and the distance of transmission reflect the advantages of rapid development and become a major power supply channels over the past decade. However, the traditional centralized power grid also has many drawbacks: highly operating costs, it is difficult to meeting our customers needing for energy reliability and security. Especially large blackouts occurred in recent years in the world, such as the 2003 blackout in the United States, the 2008 South Snowstorm and so on. The vulnerability of traditional power grid is revealed. Distributed generation have less pollution, high energy efficiency, flexible installation and so on, in addition to, distributed generation can reduce the total capacity of the grid .It can improve grid trough to peak performance and the reliability of power supply. It also is a strong complement to the large grid and effective support.

With the advent of new technologies and applications in the engineering field, especially the development of the power electronics and modern control theory is well. The concept of Micro-grid has been raised. Micro-grid combines distributed power, load, energy storage devices and control devices to form a single manageable unit, while the supply of electricity and heat to the user. Micro-grids provide technical for distributed generation and network. So Micro-grid can be seen as a new power system structure in the future, compared with the traditional centralized power, this new grid model has obvious economic and environmental benefits. Through the technology of Micro-grid can make distributed generation play its enormous potential in the power system. Micro-grid t is mainly associated with the distribution network, but it will have a profound impact in the entire power system. 


\section{The Basic Concept of Micro-Grid}

\subsection{Definition and Basic Characteristics of the Micro-Grid}

Now many countries are working on Micro-grid, the focus of development microgrid is different in many countries, so there are differences in the definition of micro-grid [1].

Table 1. US EU and Japan the Development Goals in Micro-Grid [1]

\begin{tabular}{|l|c|c|c|}
\hline \multicolumn{1}{|c|}{ Objectives } & US & EU & Japan \\
\hline $\begin{array}{l}\text { The power supply } \\
\text { reliability }\end{array}$ & $\sqrt{ }$ & \\
\hline $\begin{array}{l}\text { Reducing the impact on the } \\
\text { environment }\end{array}$ & & $\sqrt{ }$ & \\
\hline Reducing investment costs & $\sqrt{ }$ & $\sqrt{ }$ & \\
\hline $\begin{array}{l}\text { Enhancing the distributed } \\
\text { energy efficiency }\end{array}$ & $\sqrt{ }$ & $\sqrt{ }$ \\
\hline $\begin{array}{l}\text { Ensuring diversification of } \\
\text { distributed power }\end{array}$ & & $\sqrt{ }$ \\
\hline island operation & & & \\
\hline
\end{tabular}

The concept of Micro-grid is proposed by CERTS [2]. A definition was given by CERTS. Micro-grid is a system which composed of load and the Micro-power, while it can provide electricity and heat [3]. The internal power of Micro-grid is mainly responsible for the energy conversion by power electronic devices. Relatively, the external of Micro-grid manifested as a single grid controlled unit, and it meet customer requirements and supply security in power quality. This document also describes the basic structure of the system of micro-grid, control strategy, and other protective measures.

The study on the Micro-grid areas is the world leading level in Japan which caused by Japan's domestic resource constraints and increasing load [4]. So, Japan has set up NEDO. It also gives a definition. Micro-grid is compact power supply system which refers to use distributed power to provide power with user needs in certain areas. The overview of micro-grid provides a theoretical support in Japan. In accordance with the laws of the electricity market and security of supply, the EU proposed "Smart Grid" program in 2005. And the EU Framework Programme[10] gives the definition of micro-grid: By utilization primary energy, it use micropower, and cold, heat, and power supply; equipped with an energy storage device and power electronic device to regulate energy; and the network can be run in two ways and independence.

According to the definition of the relevant of Micro-grid and combining with the development situation of China's electric power system [5-9], our definition of micro-grid is one which Micro-grid is a the optimal allocation of grid by distributed power supply in the local and traditional power generation methods providing heat and electricity to nearby load and which is a system based on the traditional power of the larger independent system. Internally, the power and load of Micro-grid are controlled and in satisfying with customer requirements and supply security in 
power quality. The external of Micro-grid system is a whole unit, and can be smoothly cut the main network.

The total above, the definition of micro-grid are based on national electricity market rules and technological level so that the existing national grid more mature and stable. So that the micro-grid has become an important part of the overall power system [11], it can be seen Micro-grid as unique characteristics:

1) Unique: Micro-grid is a small system which consists of miniature power and load consisting and its advantage is the flexibility of scheduling.

2) Diversity: Miniature power of grid constitutes diversity. Either traditional power or renewable energy is involved. Meanwhile, the energy storage devices of the Micro-grid are diversity and complexity.

3) Controllability: On the basis of system operation, the Micro-grid can choose a different mode of operation and improve the reliability of the power system.

4) Interactivity: Micro-grid not only can be transported power generation equipment to the main electricity network in the necessary conditions, but also can accept the main electricity network.

5) Independence: Micro-grid can also be run independently to ensure that the local demand for electricity.

\subsection{The Basic Structure of the Micro-Grid}

Micro-grid is combined with a micro source, the load, the energy storage device, a control device and so on, consisting of a controllable unit to provide heat and power systems. Its basic structure is as follows in the Figure 1 [15].

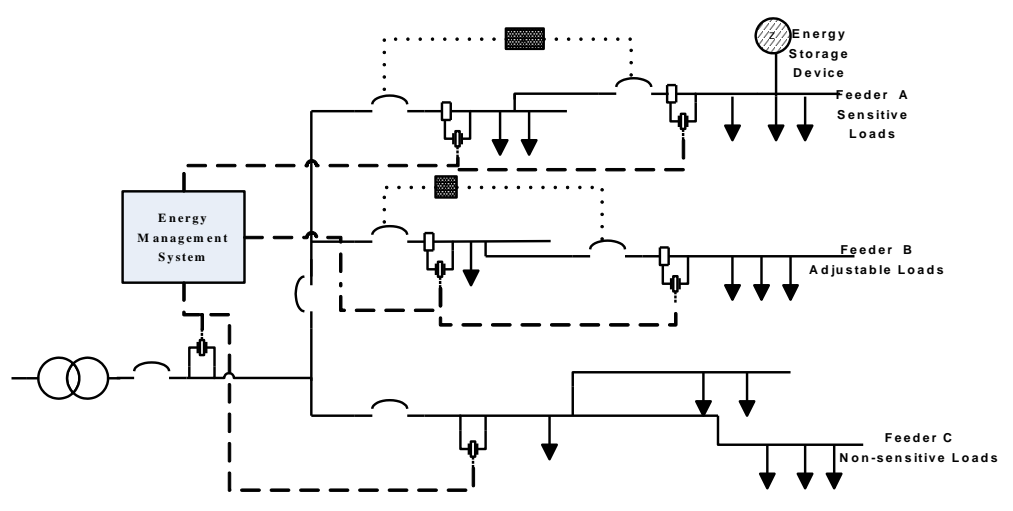

Figure 1. Basic Structure of Micro-Grid [15]

The structure contains a number of distributed power and energy storage devices. Micro-grid is a whole power grid which can be connected to a circuit breaker and a higher level through the grid.

Micro-grid structure as shown in Figure 1, the system is radial with A, B and C three feeders. The feeder is connected to the superior grid by the main isolation device of Micro-grid. It can achieve isolated operation and parallel operation of conversion. A B is an important feeder load (sensitive load) and even nuanced micro power grid. Micro power was connected with feeder A which can achieve heat, electrical double supply and provide users with heat and electricity. Feeder $\mathrm{C}$ is non-sensitive loads. If Micro-grid is overload in isolated operation, you can cut the line. Micro-grid is associated with the higher power through the main circuit breaker. Micro-grid load was borne by the micro-source in islands. If you cannot guarantee the supply and demand balance of power in the solitary network, you can 
disconnect the feeder C. Under the conditions of the grid, the interface of Microgrid and superior grid can enables power flow in both directions. When the higher electricity network fails, the Micro-grid can be quickly switch to island operation mode to offer power.

The Figure 1 of Micro-grid is just one typical pattern. In this structure, a plurality of micro-source provides voltage and electrical power to the important load. It can reduce the burden on large power transmission and can withstand the impact of large power grid failures [17]. From the main power grid analysis, micro-grid is a modular integrated unit. From the user side analysis, micro-grid is a power system with a capacity for self, which can meet different customer needs for power quality and reliability.

\subsection{The Significance of Micro-Grid}

The technology of Micro-grid can coordinate the contradiction between large grid and distributed energy and then promote the development of new energy industries so as to promote the development of China's power industry. Because the special mode of the power industry develops in country, we should not only copy foreign models for the development of the grid. But it is necessary for our country to study the grid [15].

1) Micro-grid can improve the safety and reliability of the power system. With the development of China's power industry, China's power grid has entered into the stage of large power, high-voltage, long-distance, high-capacity. It is difficult to control the dynamic stability of the accident, increasing in the likelihood of blackouts. However, Micro-grid and modern power systems can be combined to form a highly efficient and flexible in new power system. It reduces energy consumption and reduce environmental pollution .It also has flexible universities and other advantages.

2) Micro-grid can promote distributed generation and conducive to the development of new energy sources. Renewable energy development and utilization were involved in the national long-term development plan and the "Eleventh FiveYear Plan". But distributed generation faces many technical problems. Micro-grid cannot be interconnected with the big power grid which brings up the development of distributed generation. The emergence of micro-grid solves the problem of distributed generation by using the system method. This will facilitate the rapid development of distributed energy resources in China.

3) Micro-grid can improve reliability in power supply and power quality. According to the needs of end users of power, Micro-grid can provide differentiated power to form a pyramid-shaped load structure [12]. The thinking of Load rating reflects personalized in Micro-grid. Applications Micro-grid favors companies which offer different power grid and reliability of supply to various the ending of users.

\section{Micro-Power Control Strategy}

The Micro-grid contains many constraints, such as a variety of a unique distributed power, load characteristics, power quality and so on. So, Micro-power operation need to considerate many things. Micro-power usually multiples parallel interaction. In the micro power grid operation, according to the unified of power grid it can output timely voltage amplitude, frequency and phase, In island operation, the various micro-power work in the absence of a voltage reference and automatically adjust and maintain voltage amplitude, frequency stability, while according to its capacity to adjust the power output and reasonable distribute of the load to ensure uninterrupted power supply for important load. According to the 
actual situation of the micro-grid, the different types of distributed power require the use of different control methods ensure the system can run in stability, security, economical. Micro power control method usually has three ways: Control Strategy of PQ, Control Strategy of V / F and Control Strategy of Droop [14].

\subsection{Control Strategy of PQ}

PQ control can control the output of active power and reactive power. it often use in Micro-grid and network operation. Assuming a three-phase fundamental voltage of grid-connected is $u$. is the amplitude of voltage and makes Park transformation for $\mathrm{u}$.

$==$

A B C-phase voltage is coupled system in three-phase static. $\mathrm{d}$ axis component and q-axis component can be achieved the decoupling in the synchronous rotating $\mathrm{d}$ $\mathrm{q}$ coordinate. When the inverter output voltage is decided by grids, equal to a constants and $=0$.In this case, the problem of controlling in the output power of the inverter can be converted to a control of current. The power output of Active power output and reactive is determined by . It can achieve the inverter output active power and reactive power of decoupling.

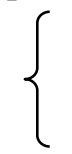

Then, the current reference value of $\mathrm{d} q$ axis component is:

$$
\{
$$

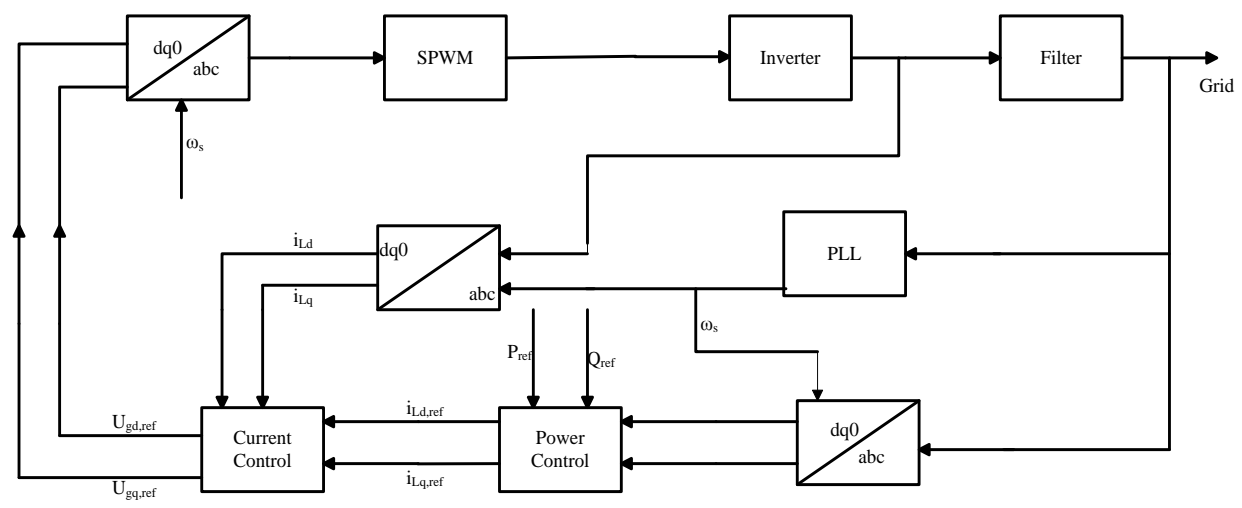

Figure 2. Block Diagram of PQ Control [13]

The principle of PQ control is shown in the Figure 2. It uses a structure which contains the outer loop of power control and the inner ring of current control. PQ control is achieved in synchronous rotation $\mathrm{d} q$ coordinate. The phase-locked loop of PLL [16] is responsible for measuring the grid frequency to seen as the reference frequency of inverter, timely tracking reference current to produce the accurate reference voltage. Filter can filter out the higher harmonics to improve the quality of distributed power [20]. SPWM is sinusoidal pulse width modulation, that is, on the basis of the duty ratio of the PWM pulse width changes by sine law. Filtered achieve sinusoidal the output of inverter. 


\subsection{Control Strategy of V/F}

Typically, inverter which works in isolated operation is controlled by V/F tactics [17]. In this state, the Micro-grid at least contains one master power to offer voltage and frequency reference of the entire independent in Micro-grid. So it can ensure voltage and frequency of micro-grid system run at a certain level [18].

The essence of $\mathrm{V} / \mathrm{F}$ control is no matter how inverter changes the output power, but required to ensure that the voltage and frequency of the inverter remains unchanged. However, due to the capacity of the islands limited, it occur the missing frequency phenomena, we must be used to ensure the important load can continue the work and can remove the secondary load. V/F control method has a highly dynamic response, which fast track complex switching and can ensure the stability of the inverter output voltage. V/F control using voltage and current dual-loop control, it can take advantage of the inverter voltage adjust current to ensure the stability of the output voltage [19]. In this case, the bandwidth of the inverter becomes large. The dynamic response of the inverter was accelerated .So it enhanced the ability to adapt in non-linear load .V/F control mode structure as shown:

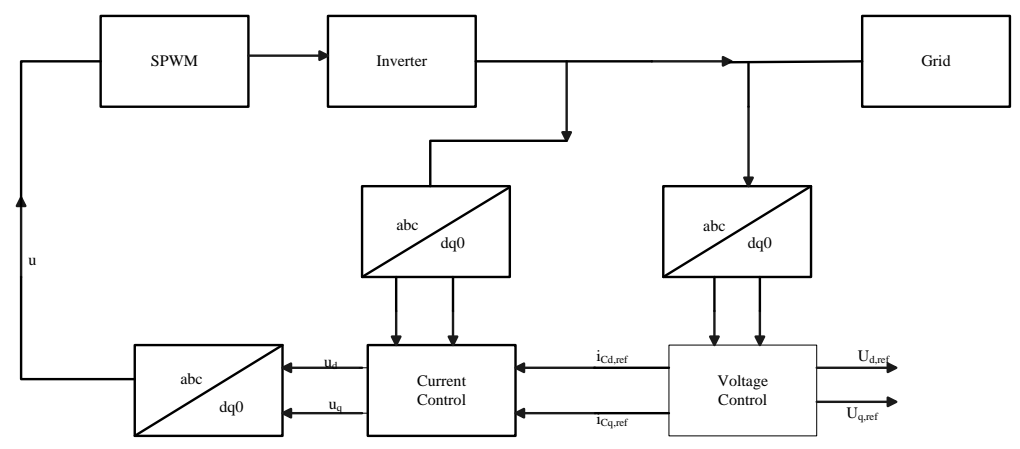

Figure 3. Block Diagram of V/F Control

\subsection{Control Strategy of Droop}

Micro-grid which contains plurality of inverters that connected in parallel by a common AC power as an export bus .According to their own needs, through the rational and optimize of the control method is respective adjusted to the output of the parallel inverter of voltage amplitude, frequency and phase in order to achieve a reasonable distribution of power between the load inverter unit. So how to deal with load changes and other interferences caused the flow and how to effectively use their information units to improve the stability and dynamic of system performance. The load characteristics were obtained electric current in good state. So, there are many tings are need to consider about the problem [21]. Droop control is mainly used in multiple parallel inverters. Inverter parallel simplified equivalent circuit diagram can be approximated $[28,30]$.

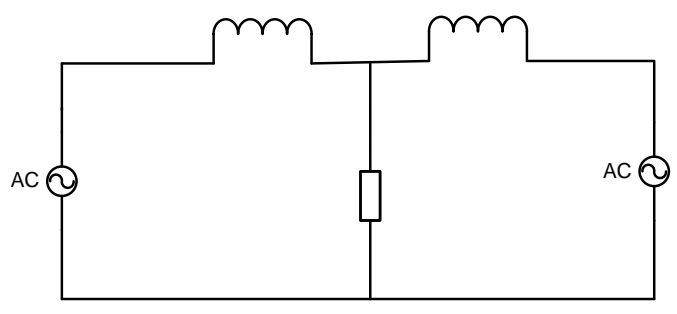

Figure 4. Inverter Units in Parallel Operation Simplified Equivalent Circuit 
Each inverter respectively exports active power and reactive power [28]:

$$
\{
$$

is the output chokes inverter; is an angle between the output voltage of the power supply voltage vector and the output voltage vector $U$ parallel system.

The reactance of the inverter output and the line impedance are compared to the load impedance which is very small. So the angle which between the inverter power supply output voltage vector and the system output voltage vector $U$ will be very small. So there is an approximate $=\delta \mathrm{n} .=1$. The above equation can be simplified as:

Can be seen from the formula: Transmission of active mainly depends on a public angle and reactive power transmission depends on the amplitude of the voltage Output voltage amplitude of the inverter unit can be directly controlled, but the phase of the inverter unit is necessary to adjust the angular frequency or frequency.

Since the inverter power of resistance is small and the characteristic of output is hard. Even a small amplitude or phase will make the parallel in inverter a great system of circulation. Using Droop control method will make the output characteristics corresponding soft [29].

It can be seen essence theory that Droop control method is following [30]. in the inverter parallel system, each inverter unit detects the size of their own power, getting feedback value of the output voltage amplitude and frequency by Droop control .The voltage amplitude and frequency of each phase should be adjust to achieve a reasonable distribution system active and reactive power.

\section{Control Strategy of Micro-Grid}

There are two modes of operation for Micro-grid [17]: Grid-connected, Autonomous Modes [30], as well as transient switching between the two modes. There are a lot of distributed power by power electronic device interface to make it poor in overload. So, it is essential to Micro-grid security and stability by fast and effective control strategies. Control strategy consists of two levels: Micro-power control and integrated control strategy of Micro-grid. Part of the control strategy on the micro-power has been fully described. The integrated control strategy of Microgrid is the overall operating performance for goal. The chapter describes several common control schemes: master-slave coercion and peer coercion.

\subsection{Master-Slave Coercion}

Master-slave control allows each micro-grid power possess different control methods [22]. one or several is master unit which can real-time monitor the power grids that contain electrical parameters and operating conditions in order to develop appropriate mitigation measures, And the operation of the other for power is 
coordinated and controlled by a communications network to ensure the entire system in a steady state.

As the result of the overall capacity of the Micro-grid compared with the distribution network is small. When Micro-grid run in network operation, the distribution network is still maintained the voltage level and frequency adjustment [20]. Each Micro-power only can export power accordance with a specified power. When entering island mode, it lost the support of the voltage and frequency of the distribution network. The stability of voltage and frequency was maintained in the internal Micro-grid. It needs one or several micro-power play a role to provide the rated voltage and frequency. So this unit is the main unit. It uses V/F to maintain the system's voltage and frequency stability, while other micro-power using PQ maintains the balance of internal power.

Master-slave operation of process control is following:

1)When the distribution network failure or the distribution networks and microgrid is disconnected, the Micro-grid enter islanding mode, while the micro-grid started master-slave control, by adjusting the output of each micro-power to achieve a new balance

2).When the load power of Micro-grid changes, first the main unit adjust the output of current to change the output of power. If others increase the output power, the main unit should reduce the output power. So as to ensure the main unit has been large enough capacity to regulate the power variation.

$3)$.When the capacity of reactive power is not enough in the grid, the main unit can only rely on to adjust. When the load power increases, the use of load voltage characteristics considered appropriate to reduce the voltage value.

Master-slave control also has disadvantages. Voltage and frequency is maintained by the master unit in the islands system. It has a large capacity power supply ensure stability of the system. In addition, the operation of the Micro-grid rely on the power of the main unit.And therefore, we should attach importance to the reliability of the main unit.

\subsection{Peer Coercion}

Peer control is that make each of the same Micro-power use the same control strategy [23]. According to the control mode which preset respective participate to adjust active and reactive power and the relationship among them are equaled. In all micro-power external characteristics, it is associated with frequency, voltage and reactive power through control algorithm and the analog adjustment mode of power grid to maintain the stability voltage and frequency of the system.

Using peer control, micro-power adjust respective the power output voltage and frequency in accordance with electrical measurements. Without coordination among interrelated micro-power, the imbalance power can be dynamically allocated power to each micro-power. The entire process does not require communication and it has the advantage of a simple, reliable and easy-to-achieve. In addition, one of the micro-power out of operation due to cause a fault, but it will not affect the normal operation of other micro-power. So, the system reliability is improved. When a new micro-grid power enters the grid, it just set the same control strategy and this can improve expansion of the system.

Peer control also has disadvantages:

1) When the load will cause an instantaneous change, it will cause a small error between the output voltage and frequency. Therefore steady state error can not reach zero, such control is actually a droop control. 
2) It cannot correctly regulate harmonics generated by distribution in non-linear loads and line loads.

3) When topology changes causes changes of control mode in the three-phase system.

Especially including a linear load and nonlinear loads, such as control of the role is limited.

According to the above analysis of the master-slave control and peer control shows that these two control modes are adapted to different operating modes of the Micro-grid. Master-slave control mode has to have strong communication links between the micro-power [32], thus it increases the cost and reduces the reliability of the system, and when the main unit breaks up, the whole system will collapse. Peer control strategy of each micro-power does not need communication links and the formation of system can be achieved to use, therefore, the control apply more extensive.

\section{The Operation of Micro-Grid}

There are two modes of operation for Micro-grid: Grid-connected and Autonomous Modes [25].

In the normal circumstances, when the Micro-grid runs in network operation, a large power grid can offer voltage and frequency, the inner of the Micro-grid works in voltage or current source state, under the mediation of the energy management system[26,27,31], It can adjust their output power. When the big power grid occur voltage dips, voltage swells, unbalance and harmonics problems or scheduled maintenance, the Micro-grid enters islanding mode [18], then the internal of microgrid should adjust the voltage and frequency. Once the fault is cleared, Micro-grid gets into a large grid.

In addition to, Grid-connected, Autonomous Modes, there is the process of converting the transition between the two modes [30]. Mode conversion process is not equaled to power restarting. Inverter continues to work to ensure a smooth transition voltage continuous within the grid by control methods and network topology grid. That is seamlessly switches to ensure that important load of internal power grid unaffected. The transition between the two modes is the conversion of the bridge and link. In transition process, power quality directly affects the operation of the network .It can ensure flexible operation to provide customized services important symbol of power in the Micro-grid system. Micro-grid runs in different operating modes. Micro-power using different control methods and network topology, which resulted Micro-grid in different operating modes and micro-power using different control methods and network topology, which resulted in conversion process diversity and uncertainty of micro power control methods [33].

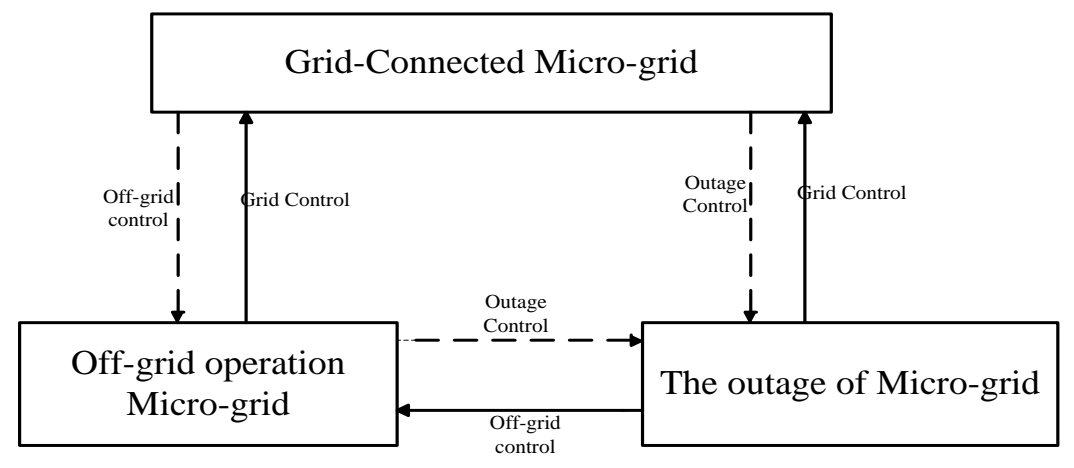

Figure 5. Micro-Grid Operation Mode 
By the Figure 5, during operation, it is possible to switch between several modes with each other and according to the different control methods. Micro-grid will switch to the appropriate operating mode.

\section{Conclusion}

With the development of Micro-grid technologies, a variety of technology and scientific research of the Micro-grid have been made in the domestic and overseas. This paper describes the operational control of Micro-grid. Firstly, it analyze the principle of micro-power control strategy which contains control strategy of PQ, control strategy of Droop and control strategy of V / F, and integrated control strategy of Micro-grid which contains master-slave coercion and peer coercion. Then, this paper research the island operation of Micro-grid and the Grid-connected operation of Micro-grid. As Micro-grid technologies continue to develop, Microgrid will be an important complement to Smart Grid in the future. The future direction of development of Smart Grid is to achieve self-healing, interactive userside and demand response. Micro-grid provides important technical support for Smart Grid. In addition, from the national energy grid transformation and enterprise development, with the development of new energy, smart grid technology and flexible power technology, the technologies of Micro-grid will have opportunities. Micro-grid as an important part of the smart grid will play an important role in the future of the grid.

\section{Acknowledgments}

This work is supported by National Nature Science Foundation of China under Grant 61372195, 61371200 and the Scientific Research Fund of Liaoning Provincial Education Department under Grant L2014526.

\section{References}

[1] Z. X. Xiao, J. Z. Wu, N. Jenkins, J. Intelligent Automation \& Soft Computing. 16, 199 (2010)

[2] J. Stevens, D. Klapp, J. CERTS Microgrid System test. 7, 112 (2005)

[3] R. H. Lasseter, J H Eto, B Schenkman, IEEE Transactions on Power Delivery, CERTS Microgrid Laboratory Test Bed. 26, 325 (2011)

[4] S. Morozumi, S. Kikuchi, Y. Chiba, C. Distribution Technology Development and Demonstration Projects in Japan of In Power and Energy Society General Meeting Conversion and Delivery of Electrical Energy in the 21stCentury; IEEE: 5, 1 (2007)

[5] K. Farid, I. Reza, H. Nikos, J. Microgrids Management. 8, 54 (2008)

[6] R. H. Lasseter, P. Piagi, J. Control and Design of Microgrid Components. 06, 3 (2006)

[7] M. Shamshiri, K. G. Chin, W. T. Chee. C. A Review of Recent Development in Smart Grid and Microgrid Laboratories of International Power Engineering and Optimization Conference; IEEE: 367, (2012)

[8] Z.X. Lu, C. X. Wang, J. Overview On Micro-grid Research Automation of Electric Power Systems. 31, 101 (2007)

[9] L. Robert, J. Micro-grids. 1, 146 (2001)

[10] F. X. Li, Q. Wei, H. B. Sun, Smart Transmission Grid: Vision and Framework of IEEE Transactions on Smart Grid, 1(2): 168-177

[11] X. H. Hu, J. Distributed Generation (Distributed Resource) Technology and Grid-connecting Issues. 2, 1 (2004)

[12] M. Begobic, C. Sustainable Energy Technological and Distributed Generation, In Proceedings of IEEE/PES Transmission and Distributed Engineering Society Summer Meeting. IEEE: 1, 540 (2001)

[13] H. Wang, Research on Operation and Control of Microgrid with Different Types of Distributed Sources. Beijing: North China Electric Power University. (2014)

[14] D. K. Brabandere, K. Vanthournout, C. Control of Microgrids Power, Engineering Society General Meeting. IEEE: 1 (2007)

[15] X. F. Yang, J. Sun, Z. P. Lv, H. T. Liu, R. Li, J. Overview on Micro-grid Technology. 34, 57 (2014)

[16] M. C. Chandorkar, D. M. Divan, A. P. Rambabu. J. Control of Parallel Connected Inverters in Standalone AC Supply Systems. 29, 136 (1993) 
[17] C. S. Wang, Z. X. Xiao, S. X. Wang, J. Synthetical Control and Analysis of Micro-grid. 32, 98 (2008)

[18] A. Shiki. Y.G. Akihiko. J. Autonomous Decentralized Control of Supply and Demand by Inverter Based Distributed Generations in Isolated Microgrid. 127, 95 (2007)

[19] P. G. Paolo, R. H. Lasseter. C. Autonomous Control of Microgrids. IEEE PES Meeting, Montreal, June (2006)

[20] R. Parikh, K. R. Medeling. J. Simulation and Analysis of an Uninterruptible Power Supply. 1, 485 (1994)

[21] J. Liu, Control Strategy for Micro-grid Operation. Henan: Henan Polytechnic University. (2011)

[22] Z. Zeng, R. X. Zhao, H. Yang, J. Micro-sources Design of an Intelligent Building Integrated with Micro-grid. 57, 261(2013)

[23] C. S. Wang, F. Gao, P. Li, J. Control Strategy Research on Low Voltage Microgrid. 32, 2 (2012)

[24] L. Su, J. H. Zhang, L. Wang, J. Study on Some Key Problems and Technique Related to Microgrid. 38, 235 (2010)

[25] Z. G. Han, Microgrid Modeling and Simulation of Its Operation and Control. Shandong: Shandong University. (2014)

[26] J. P. Lopes, A. Moreira, C. L. Madureira, C. Control Strategies for MicroGrids Emergency Operation. International Conference on Future Power Systems. 30th, Amsterdam, Netherlands: (2005)

[27] N. Hatziargyriou, H. Asano, R. Iraavani, J. al-Microgirds: an Overview of Ongoing Research Development and Demonstration Projects. 5, 78 (2007)

[28] T.C. Po, C. A. Chen, T. X. Lin, J. A Cooperative Imbalance Compensation Method for DistributedGeneration Interface Converters. 45, 805 (2009)

[29] P. G. Paolo, H. Robert, L. Lasseter, C. Autonomous Control of Microgrids IEEE PES Meeting, Montreal, June (2006).

[30] C. Jin, M. Z. Gao, X. X. Lv, C. A Seamless Transfer Strategy of Islanded and Grid-connected Mode Switching for Microgrid Based on Droop Control. IEEE Energy Conversion Congress and Exposition, 969 (2012)

[31] F. Katirei, M. R. Iravani, J. Power Management Strategies for a Microgrid with Multiple Distributed Generation Units. 21, 1821 (2006)

[32] E. Sortomme, S. S. Venkata, J. Mitra, J. Microgrid Protection Using Communication Assisted Digital Relays. 25, 2789 (2010)

[33] W. Jiang, Z. Y. He, Z. Q. Bo, C. The Overview of Research on Microgrid Protection Development International Conference on Intelligent System Design and Engineering Application, 697 (2010)

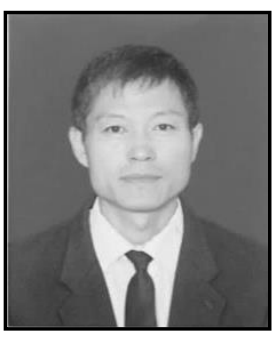

\section{Authors}

Cunxu Wang, he received his M.S degree from North China Electric Power University in 1997, and now is professor and also director in school of renewable energy, Shenyang Institute of Engineering. His research interests include theoretical analysis in solar thermal system, and also complex industry process control and automation.

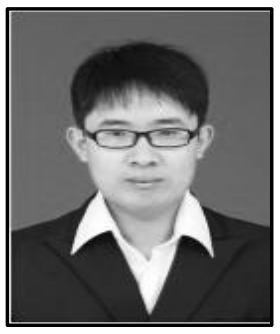

Xingfeng Xiao, he received the B.E. degree in Electrical Engineering and Automation from Linyi University, Shandong, China in 2013. He is currently working towards the Master in Electrical Engineering in Shenyang Institute of Engineering.

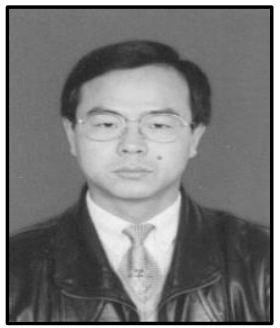

Aijun Zhang, he was born in 1970. He received Master degree, and is an associate professor. He works in school of continuing education, Shenyang Institute of Engineering. Recently, his research area contains electrical machine, control system and renewable energy technology. 


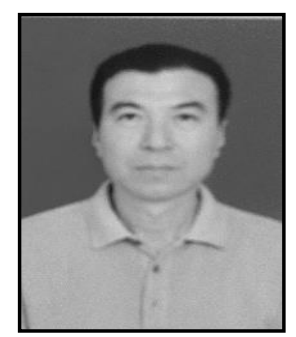

Xiaoyu Sun, he received the MBA degree from Liaoning University. He works in school of international education, Shenyang Institute of Engineering. Recently, his research area contains intelligent control, smart grid, etc. 